\title{
INTERCULTURALIDAD, MIGRACIÓN Y EDUCACIÓN EN EL MUNDO CONTEMPORÁNEO'1
}

\author{
INTERCULTURALITY, MIGRATION AND EDUCATION IN THE \\ CONTEMPORARY WORLD
}
INTERCULTURALIDADE, MIGRAÇÃO E EDUCAÇÃO NO MUNDO COMTEMPORÂNEO

Raúl Fornet Betancourt ${ }^{2}$

\begin{abstract}
RESUMEN
Trataré de exponer algunas reflexiones sobre la Interculturalidad y las migraciones contemporáneas, sus impactos y desafíos a la Educación, desde la perspectiva de la filosofía intercultural. Lo que quiere decir que mis reflexiones van a suponer una determinada percepción o comprensión del tema, ya que precisamente lo veo desde la perspectiva de la filosofía intercultural. ¿Qué quiere decir esto más en concreto? Lo siguiente: Que entiendo "interculturalidad y migraciones contemporáneas" como elementos de un contexto mayor que podemos llamar con un título general "nuestro mundo contemporáneo de hoy". Es en ese mundo donde hay "interculturalidad" y "migraciones contemporáneas". Y es desde ese contexto mayor del mundo contemporáneo que hay que reflexionar también sobre la otra parte del tema, a saber, los "impactos y desafíos a la Educación".
\end{abstract}

PALABRAS CLAVES: Interculturalidad. Migración. Educación.

\section{ABSTRACT}

In this work, I will try to expose some reflections on Interculturality and contemporary migrations, their impacts and challenges for education, starting from a perspective of intercultural philosophy. This means that my reflections will assume a certain perception or understanding of the topic, since I see it precisely from the perspective of intercultural philosophy. What does this mean, more specifically? The following: that I understand "interculturality and contemporary migrations" as elements of a broader context that we can call with the general title "our contemporary world today". It is in this world that interculturality and contemporary migrations appears. And it is from this broader context of the contemporary world that it is necessary to reflect on the other part of the theme, namely, the impacts and challenges for education.

KEYWORDS: Interculturality. Migration. Education.

\footnotetext{
${ }^{1}$ Texto de conferencia presentada en el II Coloquio Internacional Educación e Interculturalidad, en la Facultad de Educación de la Universidad de Salamanca/ESP, en abril de 2019.

${ }^{2}$ Doctorado en filosofía en Salamanca y en Aachen. Profesor de filosofía Universidad de Bremen. Profesor honorario en la Universidad de Aachen. E-mail: raul.fornet@kt.rwth-aachen.de

Submetido em: 23/01/2021 - Aceito em: 01/05/2021
}

(C) ETD-Educação Temática Digital Campinas, SP $\quad$ v.23 n.3 $\quad$ p. 581-591 jul./set.2021


1. Una aproximación crítica a lo que se llama "mundo contemporáneo", entendido como título de la configuración hoy hegemónica del mundo.

2. El "mundo contemporáneo" como un desafío para la interculturalidad y/o educación crítica intercultural.

3. Notas sobre las posibilidades de corrección u orientación de la interculturalidad en el "mundo contemporáneo".

\section{BREVE APROXIMACIÓN CRÍTICA A LO QUE SE LLAMA “MUNDO CONTEM- PORÁNEO", EN SU CONFIGURACIÓN HEGEMÓNICA}

Para nosotros los que vivimos hoy la expresión "mundo contemporáneo" hace referencia evidentemente a este período de tiempo que compartimos como conjunto "al mismo tiempo" y que, por eso, percibimos como "nuestra época". O sea que, en este sentido, la expresión "mundo contemporáneo" nos remite a lo que los antiguos latinos asociaban con el término "saeculum". Pero en la expresión "mundo contemporáneo" podemos ver igualmente una referencia al orden y/o estado de cosas que reina en la realidad y vida de la humanidad hoy; una referencia que no sólo nos remitiría al trasfondo experiencial de otros conceptos de los latinos antiguos, como los de "mundus", "orbis" o "terra", sino que nos confrontaría además con el sentido de mundo en que habla, por ejemplo, el Papa Francisco en su encíclica Laudato si cuando recuerda que el "mundo", aún hoy, no es únicamente un problema a resolver sino también de un misterio ${ }^{3}$ que confronta a sus contemporáneos con la tarea de cuidarlo como "la casa común".

De esta breve indicación sobre lo que asociamos nosotros hoy con la expresión "mundo contemporáneo", me permito subrayar ahora la idea que es más importante para la continuación de mi aclaración a la pregunta que nos ocupa en este primer paso. La idea es la siguiente:

La contemporaneidad en un mundo hace de sus habitantes "vecinos", "prójimos", en el tiempo y en el espacio, es más, los emparienta temporal y contextualmente. Pero de ahí no se deduce que el sentido ni el carácter que acompañan esa edad del mundo que les da el "aire de familia" de la contemporaneidad, se puedan explicar solamente a partir de las relaciones actuales que configuran el presente de ese tiempo del que se dice que se es contemporáneo. Debido a la historicidad que distingue lo humano, hay que decir más bien que todo presente tiene un fondo histórico; que todo "mundo" "contemporáneo", tenga o no conciencia de ello, lo es porque ha llegado a ser ese presente, porque es "heredero". Nuestra contemporaneidad no es la excepción. También ella es herencia, resultado e historia.

\footnotetext{
3 Papa Francisco, Laudato si, no 12.
}

(C) ETD-Educação Temática Digital Campinas, SP $\quad$ v.23 n.3 $\quad$ p. 581-591 jul./set.2021 
Por tanto: la comprensión de su sentido y carácter requiere un esfuerzo de remontarse más allá de la espectacularidad de las novedades e innovaciones que parecen ser la esencia de nuestra época.

Afirmo lo anterior sabiendo que, por otra parte, nuestro "mundo contemporáneo" se suele caracterizar con nombres que buscan resaltar precisamente su radical novedad como "época" o "edad" singular cuyos cambios documentarían un corte histórico, un antes y un después en la historia de la humanidad. Pensemos, por ejemplo, en nombres tan conocidos, y repetidos desde muy diferentes perspectivas disciplinares, como los de: "era atómica", "mundo científico-técnico", "sociedad de consumo", "sociedad del riesgo", "sociedad del ocio y de las vivencias", "mundo de las sensaciones", "mundo posttradicional", "mundo de la información", "mundo virtual”, "era de la digitalización ", "era del fin de las certezas", "mundo líquido", "era de la singularización y de las comunidades elegidas", "mundo del capitalismo cognitivo y cultural" etc.

Es comprensible, además, que todos estos nombres, justo debido a que pretenden reflejar de alguna manera la signatura fundamental de la época, insistan en presentarse como indicadores de la novedad radical desde la que tendríamos que comprender nuestra contemporaneidad. Y no hace falta destacar, porque va de suyo, que con todos esos nombres que resaltan la novedad, se asocian nuevos horizontes para la tarea de la educación. Pero sigamos con el punto.

Con todo, sobre el trasfondo de mi afirmación anterior y, lógicamente, sin intención de desconocer o menospreciar la real novedad de los cambios que se indican en esos nombres de nuestra época, creemos que es legítimo preguntar si esos cambios no encuentran la condición de su posibilidad en fundamentos que ellos mismos no han echado, en fundamentos teóricos y prácticos que son los pilares en que se asienta la civilización hegemónica que nos gobierna desde hace ya siglos y de la cual, por tanto, dichos cambios de hoy no serían sino manifestaciones.

Preguntando por los fundamentos que han hecho posible la novedad de nuestra época, y permitirán que lo subraye, no quiero negar ni la importancia ni las consecuencias reales que tienen los giros que se producen desde los procesos de innovación que condicionan y perfilan nuestra contemporaneidad. Más bien se trata de historizar nuestra situación, de ver de dónde viene en sus fundamentos y de poder así, eventualmente, saber preguntarnos si hemos edificado sobre una roca o sobre arena movediza, es decir, saber preguntarnos si hemos errado el camino, y dónde, cómo y cuándo. Cuestión fundamental para todo intento de fomentar una educación crítica e intercultural. 
Tal es, pues, el sentido y la intención de mi afirmación de que nuestro "mundo contemporáneo" es resultado, y de la consiguiente pregunta anterior por los fundamentos que lo han hecho posible.

Pero se me preguntará: ¿Resultado de qué exactamente? Resultado, tal sería mi respuesta, de una civilización cuyos fundamentos se remontan por lo menos al cambio de rumbo iniciado por el nominalismo de la filosofía medieval tardía y por el humanismo renacentista, especialmente italiano. En base a esta precisión, trataré, pues, a continuación, de explicar mi punto de vista enumerando brevemente algunos de los supuestos que me parecen que resuenan como los fundamentos lejanos de muchos de los procesos del modelo de civilización del que nuestra contemporaneidad forma parte. Son los siguientes:

Primero, un presupuesto que llamaré presupuesto "social-político" por el impacto que tiene - ihasta nuestros días! - en la configuración del ideal de las formas de vida, en los criterios de reconocimiento social, en el acceso a la educación, en las posibilidades de influencia en la política y la esfera pública en general, así como en la estructuración y jerarquización de la convivencia humana. Hablo de la sustitución de la pobreza como regla de vida e ideal social para habitar el mundo, por la apología de la riqueza material y del trabajo humano, visto ahora no como ordenado a la perfección, sino justamente como instrumento para la generación y el aumento de la riqueza material, es decir, del dinero y su acumulación.

Segundo, un presupuesto que llamaré "ontológico" porque abre el horizonte para una comprensión del orden de lo real y que, en síntesis, se puede resumir en la inversión del antiguo principio del "operari sequitur esse" en el de "esse sequitur operari". Se manifiesta con esta inversión que el poder del hombre es ahora el verdadero principio de realidad. Pero en esta inversión se nos anuncia ya otro presupuesto.

Tercero, un presupuesto que llamaré "antropológico-teológico" porque consiste en la contestación de la potencia de Dios con y por él ya mencionado poder del hombre, pero precisando ahora que se trata del poder de un hombre que ha tomado conciencia de sí como sujeto individual, libre y, por tanto, autónomo.

Cuarto, y como condensación de los anteriores, un presupuesto que llamaré presupuesto del "antropocentrismo idolatra" porque indica la emergencia de un hombre que busca ser únicamente el producto de su propio poder y que lanza así al mundo y a la historia un proyecto de "humanización" que exige del hombre un protagonismo tal que lo lleva a romper todos los lazos que no sean los que él mismo establece en y por su acción; protagonismo que lleva por eso no sólo a destranscendentalizar, sino también a descosmologizar, desnaturalizar e incluso descomunitarizar la realidad humana. Este tipo de ser humano gana su "reino" justo en la medida en que cancela vínculos y pierde así a Dios, al cosmos, a la naturaleza y a la comunidad.

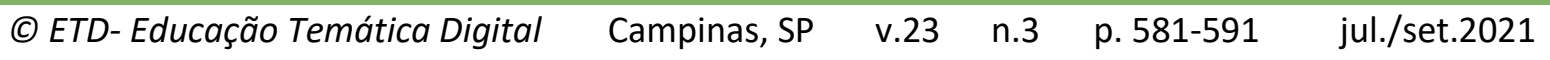


Quinto, un presupuesto que llamaré de filosofía o de teología de la historia porque tiene que ver con lo que, desde la teología cristiana, se podría denominar como la usurpación del señorío de Dios sobre el tiempo y la historia; o con lo que, desde la filosofía, podemos calificar como suplantación del tiempo que es resonancia del ritmo del Ser (Heidegger, Panikkar) por el "tiempo" programado y calculado del activismo del homo faber. Un tiempo éste último que recibe sus contenidos en y por la agenda del activismo humano y que lleva, como consecuencia, a fenómenos como los que hoy se describen bajo el signo del vaciamiento del tiempo. Pues este tiempo, que tiene sólo la función de servir de medio para el reinado del hombre sobre el mundo, ya no "trae" nada, ya no está "grávido" con ninguna promesa de esperanza y salvación, y sólo abre a lo que ha sido previsto por las expectativas de los planes del hombre industrioso.

Y preguntemos, un tanto retóricamente, ¿cómo no reconocer el impacto o la huella de esta concepción del tiempo en uno de los conceptos que con más potencia y energía mueve y determina practicamente todos los contextos de nuestro "mundo contemporáneo", a saber, el concepto o, mejor dicho, la ideología del progreso? Y, de hecho, está de sobra añadir que nos referimos al progreso en su sentido occidental hegemónico de desarrollo material y proceso de enriquecimiento, o sea, a una dinámica que paradójicamente desvaloriza el tiempo al someterlo al compás del dinero y de la acumulación de riquezas. Y observo de nuevo: aquí las consecuencias para la educación o políticas educativas son evidentes, educar para progresar.

Sexto, un presupuesto que llamaré el presupuesto de la aceptación del "ruido" como elemento y criterio de realidad y validez de realidades. Este presupuesto no se explica sin la decisión a favor de la técnica como camino regio para la cultura occidental (HEIDEEGGER, 2009; 2000). Pero prefiero no llamarlo presupuesto "técnico" o "tecnológico", porque lo que me interesa destacar aquí con él como herencia para nuestro "mundo contemporáneo" que, entre otras cosas, nos impele a estar permanentemente conectados, es precisamente la sanción social del "ruido" como forma y signo de participación en la vida. Desde entonces vamos perdiendo sensibilidad para los silencios que abren a lo sublime del mundo y del alma, y estamos más atentos al "paso de la máquina" y sus sonidos disonantes, como viera ya Hölderlin (1992). ${ }^{4}$ Otra vez aquí la pregunta para nuestra tarea: ¿Qué lugar tiene el silencio en nuestra educación?

\footnotetext{
${ }^{4}$ Cf. Hölderlin, Über die Religion; citado en: Martin Heidegger, Die Armut, Jahresgabe der Martin-HeideggerGesellschaft 1992, Verlag Vittorio Klostermann, Franfurt/M. 1992, página 4. Ver también Federico Nietzsche, Humano, demasiado humano, no.220, en Obras Completas, Editorial Aguilar, Madrid-México-Buenos Aires 1962, página 625.
}

(C) ETD- Educação Temática Digital Campinas, SP $\quad$ v.23 n.3 $\quad$ p. 581-591 jul./set.2021 
Séptimo, y por último, un presupuesto que llamaré "epistemológico" porque con él quiero resaltar la importancia del cambio de paradigma cognitivo que significó, en la cultura de la naciente modernidad centroeuropea, el paso de un conocimiento teórico y contemplativo que unía ciencia y sabiduría en su ideal de conocimiento, a un saber positivo y técnico que fragmentaba ciencia y sabiduría porque su interés cognitivo rector se dirigía al dominio y control de la realidad, y no a la perfección del ser humano. ¿Y no se refleja este cambio en nuestros planes de educación?

Hasta aquí la breve enumeración de los presupuestos o de la historia que está detrás de nuestro "mundo contemporáneo". Pasemos, pues, al segundo momento de mis consideraciones.

\section{EL “MUNDO CONTEMPORÁNEO” COMO UN DESAFÍO PARA LA INTERCULTU- RALIDAD Y/O EDUCACIÓN CRÍTICA INTERCULTURAL}

Después de lo expuesto en el apartado anterior, me parece que podemos decir de entrada que ese "mundo contemporáneo" hegemónico desafía, es más, se opone a la interculturalidad, porque está informado y formado como parte integrante de la hegemonía de la civilización occidental que traza hoy el contexto mayor de vida de la humanidad. Es, pues, su pertenencia a la civilización hegemónica lo que lo pone en oposición frente a la interculturalidad, ya que la construcción de hegemonía va pareja siempre con la opresión de la pluralidad que es también opresión de educación alternativa, y la negación de la comunicación y la convivencia interculturales. Pero veamos más de cerca esta afirmación y tratemos de explicitar su trasfondo para que se comprenda mejor la argumentación que la sostiene.

La oposición manifiesta en que, según mi interpretación, se encuentra ese "mundo contemporáneo" frente a la interculturalidad viene, ante todo, de las consecuencias teóricas y prácticas que para su concepción y configuración han tenido los supuestos nombrados. Creo que esto resulta fácilmente comprensible desde la explicación que he hecho de dichos presupuestos. Por ejemplo, en los que he llamado "presupuesto antropológico-teológico" y "presupuesto del antropocentrismo idolatra" se transparenta claramente que son el motor de procesos de estrechamiento del horizonte de la experiencia de la vida y del mundo, en cuanto que, como se indicó, cortan los lazos de unión con lo trascendente, lo cósmico o lo comunitario. $Y$ así conllevan, como consecuencia lógica de su dinámica, a la marginación o desprecio de todos aquellos universos culturales en los que resuena la fuerza vital de las relaciones que "encantan" y sostienen la vida.

Y con la misma facilidad, por poner otro ejemplo, se puede ver desde el presupuesto que llamé "presupuesto epistemológico" que con él se echan los cimientos para imponer a la humanidad una constelación del saber y sus métodos que, en nombre del rigor "epistemológico", justificará la desautorización de los conocimientos que se llamarán ahora

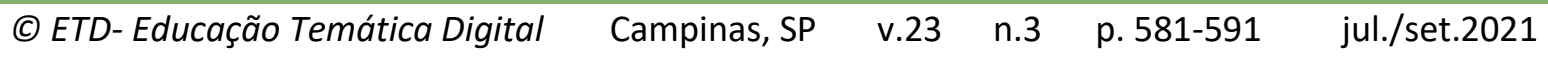


"tradicionales", quiere decir "pre-científicos", y que será, por tanto, uno de los bastiones de resistencia del "mundo contemporáneo" contra el diálogo abierto de saberes que reclama un mundo intercultural.

Estos ejemplos hacen ver con claridad que el "mundo contemporáneo" en su versión hegemónica desafía a la interculturalidad porque sus fundamentos y su proyección transpiran, para decirlo con una palabra, eurocentrismo. Lo que quiere decir que es un mundo que no pertenece a toda la humanidad; que es un mundo en cuya fundamentación y configuración no participan con el mismo derecho todas las culturas de la humanidad. Somos así "contemporáneos" de y en un mundo cuyo desafío a la interculturalidad o a la filosofía intercultural nos revela concretamente la situación de expropiación y de destierro en que vive en él gran parte de la humanidad. Y si continuamos la explicación del trasfondo de los presupuestos enumerados, podríamos ilustrar todavía esta situación señalando, por ejemplo, cómo la imposición del tiempo del progreso significa para otras culturas la expropiación de su tiempo propio.

Pero prefiero continuar la explicación de mi respuesta (el "mundo contemporáneo" desafía a la interculturalidad porque es un mundo que no pertenece a toda la humanidad), recurriendo a la caracterización que hizo el filósofo y teólogo Ignacio Ellacuría al hablar de nuestro tiempo como una "civilización del capital" (ELLACURÍA, 2000, 233-293). ¿Por qué este recurso? Porque permite ampliar lo dicho hasta ahora con una indicación fundamental que ha estado implícita en varias de las afirmaciones anteriores, pero que hay que nombrar explícitamente para saber en un sentido histórico más concreto a qué nos referimos cuando hablamos de "mundo contemporáneo". Además de que, si hablamos de que vivimos en una "civilización del capital", no se puede soslayar en un encuentro como este, los lazos de la educación con el capital.

Ante este recurso, se podrá objetar que esa caracterización de Ignacio Ellacuría nos queda ya lejos en el tiempo y que su empleo para nombrar nuestro "mundo contemporáneo" sería un anacronismo. Pero creo que esta posible objeción no tiene suelo para mantenerse en pié. La realidad la desmiente. Como sistema y "cultura" mundiales, el capitalismo hoy no solamente ha ganado en extensión, sino también en intensidad, justo con los procesos de reconfiguración del mapa del mundo que comenzaron a partir del año de la masacre en El Salvador. De suerte que hay que decir más bien que la caracterización de Ignacio Ellacuría es hoy más certera y "actual" que cuando la expuso en el año de 1989. Esto es, sin duda, parte de la tragedia de la historia que escribe hoy la humanidad. Bien:

Ignacio Ellacuría hablaba de nuestra civilización en los términos precisos de una "civilización de la riqueza y del capital" (ELLACURÍA, 2000, p. 273). Y creo que, como decía, con ello da una pista fundamental para comprender de una forma más concreta la génesis y el carácter de los procesos vinculados con los presupuestos que hemos presentado como
(C) ETD- Educação Temática Digital
Campinas, SP
v. 23
n.3
p. 581-591
jul./set.2021 
pilares de nuestro "mundo contemporáneo". Además, y este es el aspecto de su caracterización que me interesa destacar ahora, la indicación de vivimos en una civilización capitalista nos ayuda a complementar nuestra afirmación sobre la adversidad de nuestro mundo contemporáneo, añadiendo que nuestro "mundo contemporáneo" es un desafío para la interculturalidad no sólo porque es eurocéntrico, sino también por ser capitalista.

A la hegemonía europea/norteamericana se une así la hegemonía del capital como componente de nuestro "mundo contemporáneo".

De donde se sigue también que la respuesta dada arriba cuando decía que el "mundo contemporáneo" se opone a la interculturalidad porque no pertenece a la humanidad, se puede complementar y radicalizar ahora añadiendo que es porque pertenece al capital por lo que no pertenece a toda la humanidad.

Se ve, así, como un análisis detenido de las razones por las que el "mundo contemporáneo" es un desafío a la interculturalidad conduce a la pregunta política posiblemente más "impertinente" que se pueda hacer hoy. La pregunta:

¿Quién manda en el "mundo contemporáneo"? O, preguntando con más claridad todavía: ¿A quién pertenece el "mundo contemporáneo"?

Para Ignacio Ellacuría la respuesta era evidente, como parece deducirse del título de su famoso "Editorial": "A sus órdenes, imi capital"! (ELLACURÍA, 1976, p. 637-648). Y el debate actual de esta cuestión parece darle la razón (JAKOBS, 2017). Aquí no entraré en este debate. Sólo quiero indicar que precisamente para la cuestión de las posibilidades de una educación crítica e intercultural es de suma importancia saber quién "manda" en el mundo y saber qué educación conviene a su poder de mando, esto es, para continuar gobernando la humanidad. Pues de eso depende lo que tratamos en nuestro tercer punto.

\section{NOTAS SOBRE LAS POSIBILIDADES DE CORRECCIÓN U ORIENTACIÓN DE LA INTERCULTURALIDAD EN EL “MUNDO CONTEMPORÁNEO”}

Se preguntan en una discusión en la década de 1960 Jean-Paul Sartre y Simone de Beauvoir sobre qué puede la literatura en el mundo de su época y respondía con un llamamiento y un testimonio de compromiso político (SARTRE; BEAUVOIR, 1996). Acaso nosotros podamos responder de manera similar y esbozar prácticas de compromiso a favor de un mundo realmente equilibrado por la buena convivencia entre las diferencias. Considerando las posibilidades de este compromiso desde el tema de este encuentro, cabe señalar que la interculturalidad puede y debe ayudar a corregir las pautas educativas hegemónicas desde el diálogo con los migrantes, mostrando otro mapa del mundo, es decir, mostrando que el mundo contemporáneo no es su sistema hegemónico y sus "márgenes" en la periferia, porque las culturas, saberes y costumbres que vienen con los migrantes no son

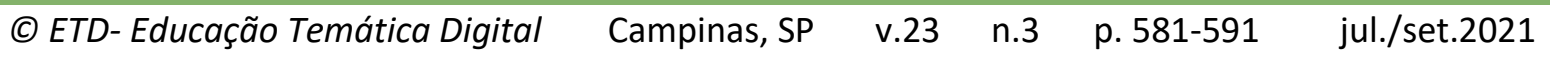


"márgenes", sino precisamente manifestaciones de los otros muchos mundos posibles. Esto es: con la migración se nos ofrece la posibilidad real y concreta de encontrar otros puntos cardinales para la orientación general en nuestro mundo de hoy y por tanto también para una renovación de la educación. Así, reconocer la humanidad de los migrantes debería implicar también reconocer los nuevos puntos cardinales que se nos abren con su presencia.

Orientar la educación desde esos otros puntos cardinales da a la interculturalidad la posibilidad más concreta todavía de enfocar la educación no desde el desafío de ampliarla para que también quepan en ella elementos de la diversidad del mundo, sino desde el desafío de restituir a la humanidad el peso real de los lugares donde el hombre se ha hecho y se hace humano y que son, por eso, no sólo herencia, sino además presencia de más humanidad.

En este sentido no se trataría tanto de promover una educación para que la gente sea más tolerante en la civilización actual, sino más bien una educación que prepare para que podamos crecer en humanidad. Pero una educación crítica con esta finalidad tendrá que ser consciente de que el fondo lo que reclama es liberar la educación de su servilismo a la civilización del capital. ¿Podremos educar para que la gente pida ilibertad de civilización! ¿Y no simplemente un lugar en ella?

Creo que sí es posible, pero a condición de que por la interculturalidad aprendemos también que, aunque los muertos no necesitan ya de educación, ellos sí tienen un lugar en nuestra educación por lo humano acumulado que simbolizan.

\section{OBSERVACIÓN FINAL}

Termino con una muy breve observación. Se entenderían mal las consideraciones expuestas si se supusiese que apuntan a una transformación cognitiva del hombre actual, pues, aunque lo contemplen, su intención es la de motivar a un cambio afectivo, a un cambio en la orientación afectiva del alma humana. El reto más profundo es hacer de la experiencia de la interculturalidad como disposición para corregir el estrechamiento de la humanidad del hombre que sufrimos hoy, el centro de una pedagogía de nuevos afectos. Y por ello la pregunta fundamental sobre la que tenemos que reflexionar en sentido autocrítico es está:

¿Sentimos nosotros como contemporáneos de la humanidad de nuestros días afectivamente la necesidad de vivir la interculturalidad como experiencia de ensanchar lo humano para ser más, es decir, enteramente humanos?

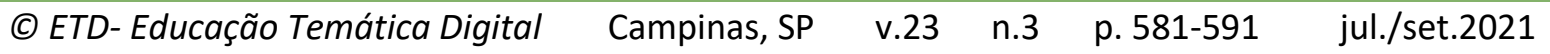




\section{REFERENCIAS}

ELLACURÍA, Ignacio. A sus órdenes, mi capital. Revista "Estudios Centroamericanos" - ECA, San Salvador, p. 637-648, 1976.

ELLACURÍA, Ignacio. Utopía y profetismo desde América Latina. Un ensayo concreto de soteriología histórica. Escritos Teológicos, tomo II. San Salvador: UCA Editores, 2000. p. 233-293.

HEIDEGGER, Martin. Die Frage nach der Technik. Vorträge und Aufsätze, Gesamtausgabe, tomo t, Vittorio Klostermann, Frankfurt/M. 2000, p. 5-36.

HEIDEGGER, Martin. Leitgedanken zur Entstehung der Metaphysik, der neuzeitlichen

Wissenschaft und der modernen Technik. Gesamtausgabe, tomo 76, Vittorio Klostermann, Frankfurt/M. 2009.

HÖLDERLIN, Friedrich. Über die Religion. In: HEIDEGGER, Martin. Die Armut. Jahresgabe der Martin-Heidegger-Gesellschaft 1992.

JAKOBS, Hans-Jürgen. Wem gehört die Welt?: Die Machtverhältnisse im globalen Kapitalismus. Knaus Verlag, München, 2017.

NIETZSCHE, Frederico. Humano, demasiado humano. №. 220, Obras Completas. Madrid; México; Buenos Aires: Editorial Aguilar, 1962.

PAPA FRANCISCO. Laudato si: sobre el cuidado de la casa comum. №. 12, 2015.

SARTRE, Jean-Paul; BEAUVOIR, Simone de. ¿Para qué sirve la literatura? Buenos Aires: Editorial Proteo, 1996.

Revisión gramatical: Karine Taiza Mendes

Correo electrónico: Karine ktm@hotmail.com

(C) ETD-Educação Temática Digital Campinas, SP $\quad$ v.23 $\quad$ n.3 $\quad$ p. 581-591 jul./set.2021 